\title{
Clinical Impacts of Myocardial Injury After Noncardiac Surgery on Younger Generation
}

\author{
Shunsuke Kawamoto, MD, PhD
}

$\mathbf{P}$ erioperative cardiovascular events are a major cause of 30-day death after noncardiac surgeries. Myocardial injury after noncardiac surgery (MINS) was proposed in 2014 based on the Vascular Events in Noncardiac Surgery Patients Cohort Evaluation (VISION) study. ${ }^{1,2}$ MINS is defined as an elevated postoperative troponin measurement due to myocardial ischemia (i.e., supply-demand mismatch) or thrombus during or within 30 days after noncardiac surgery and has been reported to be associated with an increased risk of death and major vascular complications at 30 days and even up to 2 years after noncardiac surgery. According to the VISION study, $8.0 \%$ of patients who underwent noncardiac surgery experienced MINS. More than 200 million adults worldwide undergo major noncardiac surgery annually, suggesting that over 16 million adults may experience MINS annually.

MINS includes a wide spectrum of acute coronary events with the background of coronary arterial pathology (Figure); therefore, several studies have suggested that patients with MINS may benefit from administration of low-dose aspirin, statin, $\beta$-blocker, and angiotensin-converting enzyme inhibitor. ${ }^{3-5}$ Moreover, a trial published in 2018, an international, randomized, placebo-controlled trial that investigated the preventive effects of anticoagulation therapy in patients with MINS, demonstrated that dabigatran $110 \mathrm{mg}$ twice daily could help patients with MINS by reducing the risk of a major vascular complication. ${ }^{6}$ These medical interventions, combined with coronary revascularization, may potentially improve outcomes after MINS, although more randomized controlled trials need to be conducted to confirm it.

The investigations of MINS have been based on the landmark analysis of the VISION study, ${ }^{1,2}$ which prospectively enrolled 15,065 patients from multiple countries, but focused only on patients aged $>45$ years. Many guidelines on perioperative cardiovascular evaluation and management of patients undergoing noncardiac surgery published in 2017, including the Japanese Guidelines, have not recommended routine postoperative cardiac troponin monitoring in unselected patients, suggesting it should be limited to patients with high-risk status and aged $>65$ years. ${ }^{7-9}$

In this issue of the Journal, Park et a ${ }^{10}$ investigate the associations of MINS with deaths after noncardiac surgery

\section{Article p 2081}

in patients aged $<45$ years. In their single-center observational study, which focused mainly on neurosurgeries, vascular surgeries, and gastrointestinal surgeries, the incidence of MINS was significantly lower in patients aged $<45$ years, but the prognosis in these patients was worse than that of patients aged $\geq 45$ years. Although surgical invasiveness tends to be greater in patients aged $<45$ years and its influence of that on 30-day mortality after surgery needs to be rigorously examined, the short-term mortality rates were dependent on the occurrence of MINS rather than on age, indicating that MINS may have consistent prognostic influence even in patients aged $<45$ years as well as older patients.

Because of the definition of MINS and perioperative use of narcotics and analgesics, only $9-15.8 \%$ of patients with MINS presented specific ischemic findings such as chest pain/oppression and ECG change., ${ }^{, 6}$ Nearly $90 \%$ of MINS cases are asymptomatic, which is thought to be caused by a supply-demand mismatch and probably would be undetected without intentional troponin monitoring after surgery. Some coronary artery lesions (plaque formation and endothelial dysfunction) are considered the pathological background in these patients with MINS. Diseased coronary arteries cannot supply enough blood to meet the increased perioperative demand of noncardiac surgery, resulting in ischemia. Therefore, MINS can be interpreted as an indicator of functional coronary artery lesions that could cause a supply-demand mismatch, even though it may not have been highlighted by the preoperative examination. The preoperative risk of coronary arteries is not higher in patients aged $<45$ years than in those aged $\geq 45$ years, and it is impractical and invasive to universally evaluate coronary artery lesions before surgery. To detect/ identify most cases of asymptomatic MINS among young patients, it might be realistic to check an abnormal increase in cardiac troponin level after noncardiac surgeries. A cost-consequence analysis based on the VISION data and another economic analysis have suggested that it could be reasonable/acceptable to measure cardiac troponin after noncardiac surgeries comparing the serious consequences in patients $\geq 45$ years who underwent noncardiac

The opinions expressed in this article are not necessarily those of the editors or of the Japanese Circulation Society.

Received May 6, 2021; accepted May 6, 2021; J-STAGE Advance Publication released online June 12, 2021

Division of Cardiovascular Surgery, Faculty of Medicine, Tohoku Medical and Pharmaceutical University, Sendai, Japan

Mailing address: Shunsuke Kawamoto, MD, PhD, Division of Cardiovascular Surgery, Faculty of Medicine, Tohoku Medical and

Pharmaceutical University, 1-15-1 Fukumuro, Miyagino-ku, Sendai 983-8536, Japan. E-mail: kawamoto@ tohoku-mpu.ac.jp

All rights are reserved to the Japanese Circulation Society. For permissions, please e-mail: cj@j-circ.or.jp

ISSN-1346-9843 


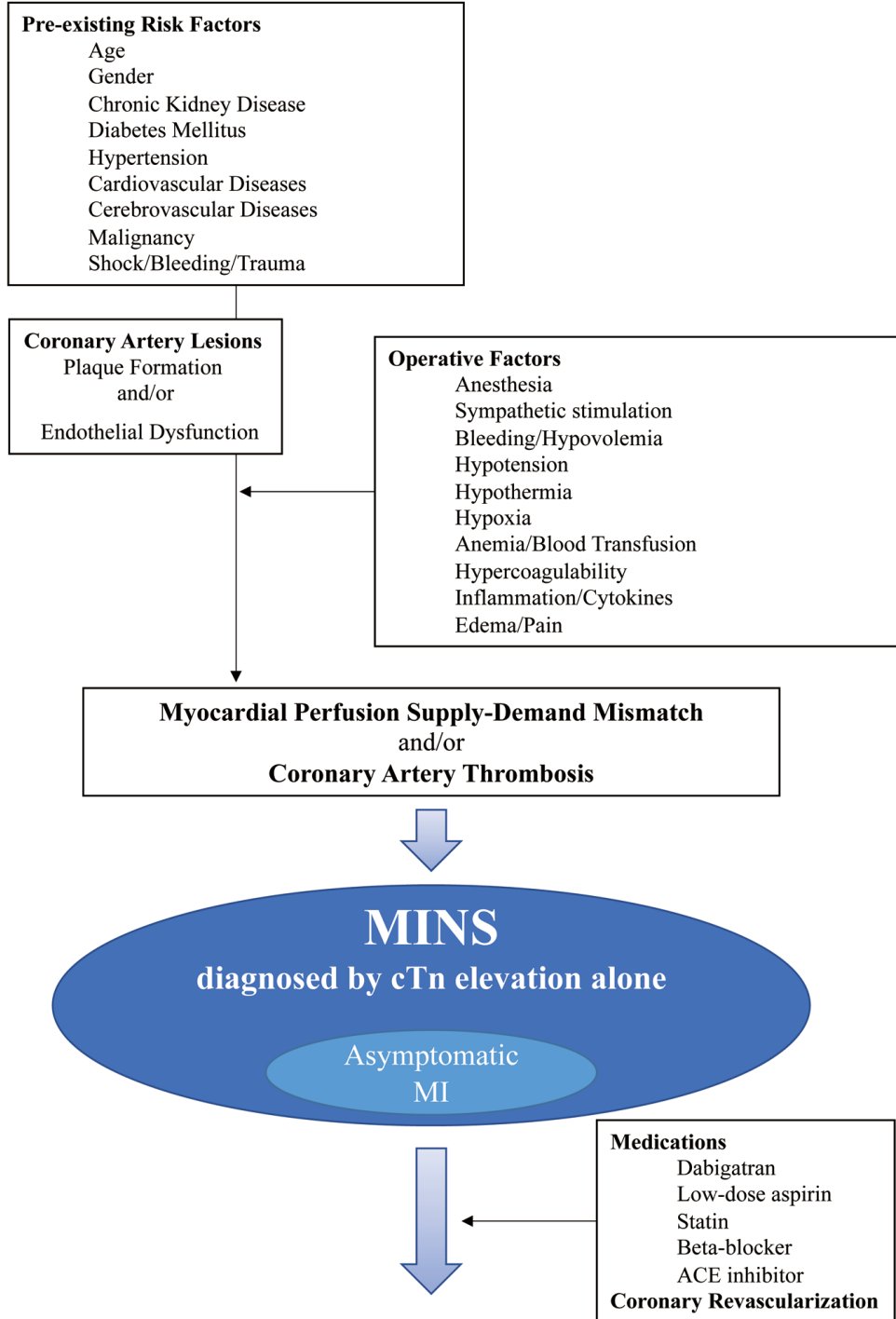

Improve Prognosis after Non-cardiac Surgery
Figure. Pathophysiologic schema of myocardial injury after noncardiac surgery (MINS). cTn, cardiac troponin; MI, myocardial infarction. surgery. 2,11

To improve the outcomes of noncardiac surgeries, early detection and interventions of MINS are definite targets. Further multicenter prospective studies, including a costeffectiveness analysis involving patients aged $<45$ years and wider variety of surgeries, are necessary to expand the screening of perioperative troponin elevation to younger generations and to establish effective interventions against cardiovascular events after MINS. In addition, surgeons in various field, as well as intensivists, anesthesiologists, and cardiologists, should pay more attention to MINS.

\section{Acknowledgment}

The author thanks Enago (www.enago.jp) for English language review.

\section{Disclosures}

The author declares no conflicts of interest in association with the present article.

\section{References}

1. Vascular Events In Noncardiac Surgery Patients Cohort Evaluation Study Investigators, Devereaux PJ, Chan MT, Alonso-Coello P, Walsh M, Berwanger O, Villar JC, et al. Association between postoperative troponin levels and 30-day mortality among patients undergoing noncardiac surgery. JAMA 2012; 307: 2295-2304.

2. VISION Study Investigators, Botto F, Alonso-Coello P, Chan MT, Villar JC, Xavier D, Srinathan S, et al. Myocardial injury after noncardiac surgery: A large, international, prospective cohort study establishing diagnostic criteria, characteristics, predictors, and 30-day outcomes. Anesthesiology 2014; 120: $564-578$.

3. Devereaux PJ, Xavier D, Pogue J, Guyatt G, Sigamani A, Garutti I, et al. Characteristics and short-term prognosis of perioperative myocardial infarction in patients undergoing noncardiac surgery: A cohort study. Ann Intern Med 2011; 154: 523-528.

4. Foucrier A, Rodseth R, Aissaoui M, Ibanes C, Goarin JP, Landais $\mathrm{P}$, et al. The long-term impact of early cardiovascular therapy intensification for postoperative troponin elevation after major vascular surgery. Anesth Analg 2014; 119: 1053-1063.

5. Devereaux PJ, Szczeklik W. Myocardial injury after non-cardiac surgery: Diagnosis and management. Eur Heart J 2020; 41: $3083-3091$ 
6. MANAGE Investigators, Devereaux PJ, Duceppe E, Guyatt G, Tandon V, Rodseth R, Biccard BM, et al. Dabigatran in patients with myocardial injury after non-cardiasurgery (MANAGE): An international, randomised, placebo-controlled trial. Lancet 2018; 391: $2325-2334$.

7. Kyo S, Imanaka K, Masuda M, Miyata T, Morita K, Morota T, et al; on behalf of the Japanese Circulation Society Joint Working Group. Guidelines for perioperative cardiovascular evaluation and management for noncardiac surgery (JCS 2014): Digest version. Circ J 2017; 81: 245-267.

8. Fleisher LA, Fleischmann KE, Auerbach AD, Barnason SA, Beckman JA, Bozkurt B, et al. 2014 ACC/AHA guideline on perioperative cardiovascular evaluation and management of patients undergoing noncardiac surgery: A report of the American
College of Cardiology/American Heart Association Task Force on Practice Guidelines. Circulation 2014; 130: e278-e333.

9. Duceppe E, Parlow J, MacDonald P, Lyons K, McMullen M, Srinathan S, et al. Canadian Cardiovascular Society guidelines on perioperative cardiac risk assessment and management for patients who undergo noncardiac surgery. Can J Cardiol 2017; 33: $17-32$.

10. Park J, Kwon J, Lee SH, Lee JH, Min JJ, Kim J, et al. Prognosis of myocardial injury after non-cardiac surgery in adults aged younger than 45 years. Circ J 2021; 85: 2081 - 2088 .

11. Torborg A, Ryan L, Kantor G, Biccard BM. The pharmacoeconomics of routine postoperative troponin surveillance to prevent and treat myocardial infarction after non-cardiac surgery. $S \mathrm{Afr}$ Med J 2014; 104: 619-623. 